\title{
CANCER RESEARCH IN THE FAR EAST
}

\author{
E. Boyland, D.Sc. \\ Professor of Biochemistry, Institute af Cancer Research, Royal Cancer Hospital, Fulham Road, London, S.W.3
}

WITH the recognition of the widespread incidence of cancer, research into its occurrence, cause and treatment is being pursued in an increasing number of centres. This research is supported by governments, by industry and by private subscription. The biggest effort is undoubtedly being made in the United States of America where very large sums of money are being spent, particularly in the field of chemotherapy of cancer; this is financed mainly by the government United States Health Service and the American Cancer Society which relies on private donations. One had the impression that the support of cancer research in Japan was to some extent dependent on industry. Cancer research in China is necessarily entirely under government support and control, but some of the buildings used for the research in Chinese cities were originally provided by western benefactions.

\section{Japan}

Cancer research in Japan has a relatively long history. The original work of Yamagiwa and Ichikawa (1916) carried out almost 50 years ago showed that coal tar would induce cancer when painted on the ears of rabbits. Later Tsutsui (1918) showed that painting of tar on the backs of mice induced skin tumours. These findings have been the basis of subsequent work in the study of carcinogenesis, particularly in the field of polycyclic hydrocarbons. Dr. C. Huggins suggested to me that the Japanese workers succeeded in the induction of cancer in animals when western investigators had failed to do this for two reasons: the Japanese were accustomed to painting because they wrote with a brush; and they are extremely persistent. The induction of cancer in animals takes many months or even years. Later Yoshida (1934) and Kinosita (1940) showed that certain azo dyes such as ortho-aminoazotoluene and butter yellow (4-dimethylaminoazobenzene) can induce cancer of the liver. This work has led to investigations in many countries on the genesis of liver cancer.

Most of the present-day cancer research in Japan is concerned with epidemiology and chemotherapy. Cancer of the stomach and cancer of the liver occur more frequently in Japan than iñ? western countries; the elucidation of the causes of these forms of cancer presents important, interest ing, but difficult problems which are being studied. The incidence of these forms of cancert appears to be influenced by diet, but the relation 3 ship between diet and cancer in man remains. obscure. One of the dietary factors suspected as possibly responsible for cancer in man is yellowed or mouldy rice. One of the moulds which is commonly present in rice stored in damp condi-क tions is Penicillium islandicum. Feeding of rices artificially infected with the penicillium induced $a$ few tumours in rats. Consumption of mouldye rice might conceivably play a part in the induction of cancer in man (Miyake, Saito, Enomoto, Shikata, Ishiko, Uraguchi, Sakai, Tatsuno, Tu\&\& ioka and Noguchi, 1960).

Investigations in the field of cancer cheno -0 therapy in Japan have been mainly along two lines; the alkylating agents and antibiotics. Among the alkylating agents the Japanese drug Nitromin which is an N-oxide of nitrogen mustard ( $\left.\mathrm{HN}_{2}\right) \stackrel{\mathrm{Q}}{\Omega}$ was introduced by Ishidate, Kobayashi, Sakurai $\overrightarrow{\vec{B}}$ Sato and Yoshida (195I) and has been usedB extensively in the East. Nitromin is probablye inactive as such, but is reduced in the body to the active nitrogen mustard. Nitromin is much lesso toxic than nitrogen mustard and can be adminis 3 . tered by mouth; it appears to be a useful drug in the treatment of lymphoid tumours. Another. interesting development in the study of nitrogeno mustard derivatives is that of Sakurai ( $196 \mathrm{r}$ ) who has synthesised a series of chloroalkyl chloroethylamines with different alkyl groups with differ $\rightarrow$ ? ent numbers of carbon atoms varying from two to‥ six. These compounds have, up till now, onlyn been tested in animals. Antitumour activity occurred with compounds with a side chain with $3,4,5$ or 6 carbon atoms. Benzyl-(2-chloroethyl) $-\underbrace{N}$ (6-chlorohexyl) amine and benzyl-(2-chloroethyl) 2 (3-propyl) amine inhibited the growth of tumourso in rats. These compounds are examples of a new type of drug and it will be interesting to see if they have any clinical value.

Japanese chemists and biochemists have isolated many antibiotics or fermentation products with 
interesting properties. One of these substances, Mitomycin C, although extremely toxic, inhibits tumours in sub-toxic doses. The chemical structure of Mitomycin $\mathrm{C}$ has not been determined but it has been used clinically in some hundreds of cancer patients and has produced beneficial effects in some of these. Mitomycin $\mathrm{C}$ is administered by injection and the total dose used in a course of treatment should not exceed $40 \mathrm{mg}$. Japanese workers are actively investigating different fermentation products from the point of view of chemistry and pharmacology. In Japan there is often close co-operation between workers in University laboratories and the pharmaceutical industry.

Takizawa and Murayama (1960) have described the induction of sarcomata in rats by injection of hypertonic solutions of different reducing sugars such as mannose or galactose, but not with sucrose. In these experiments the incidence of tumours was always low-generally below the usually accepted level of statistical significance. The occurrence of these tumours has frequently been used as indicating that injection experiments are of little value in testing of food additives for carcinogenic activity. The action of these solutions may be due to the physical effect of the osmotic pressure; the observations present interesting problems which deserve further investigation.

\section{China}

Cancer research in China started on a large scale some three years ago when the authorities considered that the problems of infectious diseases were being sufficiently investigated. The Academia Sinica has laboratories in several Chinese cities which carry out investigations in many fields of pure and applied science. The laboratories in Shanghai, which occupy buildings which used to be the Lester Institute, are devoted to biology and biochemistry. In these laboratories, which are well equipped with apparatus from all over the world (including the U.S.A.), there are a number of scientists who have worked in Britain or America in the past. Thus the physiology department is under the direction of Dr. Feng, who had worked with Prof. A. V. Hill in London and Dr. Bronk in Philadelphia. The biochemistry department was run by Dr. Y. C. Wang, who had worked with Prof. Keilin and Dr. T. C. Tsao, who had collaborated with Dr. K. Bailey in Cambridge. Most of the research in the biochemistry department is of a fundamental nature, on the problems of protein synthesis, the isolation and nature of proteins from blood and tissues (particularly muscle and brain), and enzyme action including proteolysis and oxidation processes. The only cancer problem being studied appeared to be the polarographic test for cancer diagnosis which had been introduced in Prague.

There are about 30 graduates in the department of experimental biology of the Academia Sinica at Shanghai working on cancer research. Most of the problems on which they are engaged are also being studied by many workers in other countries. Thus they are studying the polyoma virus in animal and human tumours by injecting tumour extracts into young rats, mice and hamsters, and applying extracts to normal cells growing in tissue culture. The human tumours investigated were mostly hepatomas-none of the extracts had produced tumours in animals, but extracts of one human liver cancer had induced abnormalities in tissue cultures. They are also examining the pre-cancerous changes in experimental liver cancer in rats, particularly in relation to the type of liver damage which precedes and is associated with hepatoma development following treatment with acetylaminofluorene and other agents under different dietary conditions. Another team in this department were studying the immunological reactions of cell fractions from normal and malignant tissues. The reactions were being measured by complement fixation, by anaphylactic responses and by precipitin reactions. In the tissue culture laboratory (under the direction of Dr. Chen who at one time had worked with Dr. H. Fell at the Strangeways Institute, Cambridge), 22 different strains of cells were maintained.

The department of Materia Medica of the Academia Sinica in Shanghai has a total staff of 500 , of which about 100 are graduates in either science or medicine. There are extensive facilities for animal experimentation and many new compounds and preparations are tested for possible application in the treatment of infectious diseases, cardiovascular diseases and cancer. In the cancer chemotherapy screening programme a range of Io different animal tumours were employed. One of the lines of approach was the synthesis of nitrogen mustard derivatives of local anæsthetics; this work is under the direction of Dr. Y. S. Kao who had worked with Sir Robert Robinson in Oxford some years ago. Another group of workers were preparing extracts from native Chinese plants. Extracts of the Chinese plant Narcissus Tazita var. Chinesis Rhoeme have been found to inhibit the growth of transplanted tumours in animals. The active principle from the narcissus has not been isolated but it appeared to have some of the biological properties of colchicine.

Cancer research in Peking is mainly under the direction of the Academy of Medical Science, which is in part housed in the old Peking Union Medical College and a cancer hospital, which was 
built only three years ago in the eastern suburbs of the city. This hospital has 200 beds and is equipped with a cobalt bomb unit from Canada and X-ray apparatus from many countries. About Ioo doctors are attached to the hospital, but many of these are under training, as the centre is used to give instruction in treatment of cancer for doctors ffom all over China. The cytology laboratory had a staff of four workers who were using the Papanicolaou technique for the detection of cancer of the cervix.

Cancer of the cervix is one of the common forms of cancer in China. Investigations on the epidemiology of cancer in China are difficult in view of the large area and population of the country, but this has begun in certain limited areas of the country. Other forms of cancer which appear to be peculiarly common are cancer of the œsophagus in North China and cancer of the nasopharynx in South China and other countries of South-East Asia. Nasopharyngeal cancer is a particularly interesting problem. The occurrence of the disease is compatible with there being some environmental or similar causes. Suggested causes of this disease are the incense from burning joss-sticks, the smoke from wood or other fuels used in cooking, the consumption of particularly hot (either in temperature or flavour) food, or the morphology of the nose in Chinese and other races in South-East Asia. Some investigators consider that the disease only occurs in persons living near the sea. Most of the cases occur in cities such as Shanghai, Canton, Hong Kong and Singapore.

In view of the current interest in polyoma virus it might be of value to examine tissue from nasopharyngeal cancer for the presence of a tumourinducing virus. The disease is not limited to Chinese, as the incidence of the disease in Singapore and Kuala Lampur is similar in the Malayan and Chinese populations.

\section{Hong Kong}

Although most of the cancer research in the Far East is carried out in China and Japan, ำ interesting work is proceeding in other centres. In $\bar{\Phi}$ Hong Kong Prof. Hou and Dr. Ma Lin are $\frac{\varrho}{c}$ investigating the genesis of liver cancer. Post $-\stackrel{-}{\rightarrow}$ mortem and other examination of subjects with liver cancer indicate that there is an association? between infection with clonorbis and liver cancer. 흠 Infection with clonorbis arises from eating raw $\frac{\bar{c}}{\bar{T}}$ fresh water fish. The fish were fed on human $\stackrel{\mathbb{\Phi}}{\Omega}$ fæces so that there was a cycle which led to continuous fresh infection. By preventing the $\rightarrow$ eating of the particular raw fish, it is thought that. the incidence of liver cancer from this source $\vec{\omega}$ should be reduced. The organisms themselves ${ }^{\circ}$ isolated from livers of infected patients and of $\overrightarrow{0}$ infected cats have been investigated by chemical 3 . analysis. The organisms appear to have a very high copper content.

Cancer of the liver occurs much more frequently in Africa and Asia than in Europe and America. Prof. Macfadzean in Hong Kong has found that the presence of liver cancer often has profound 을 effects on carbohydrate metabolism of the subject. Patients with liver cancer frequently have muscular $\subseteq$ weakness, which can be reversed by administra- $\overparen{D}$ tion of insulin. It is remarkable that liver cancer $\vec{\theta}$ should effect carbohydrate metabolism of th whole body.

The problems of the origin, nature and treat ment of cancer are of universal interest and development of many of these would be facilitated by good international co-operation. Such cooperation, particularly between the East and West, is helped by interchange of workers between different countries. It is to be hoped that there will be more opportunity for young research workers from Eastern countries to work in American, British or European laboratories in the next few years.

\section{REFERENCES}

Ishidate, M., Kobayashi, K., Sakurai, Y., Sato, H., and Yoshida, T. (195 I): Experimental Studies on Chemotherapy of Malignant Growth employing Yoshida Sarcoma Animals. II.-The Effect of N-oxide Derivatives of Nitrogen 0 Mustard, Proc. Fapan Acad., 27, 493.

Kinosita, R. (I940): Studies on Carcinogenic Azo and Related Compounds, Yale Y. Biol. Med., I2, 287.

Mryake, M., Saito, M., Enomoto, M., Shikata, T., Ishiko, T., Uraguchi, K., Sakai, F., Tatsuno, T., Tuskioka, M., O and Noguchi, Y. (1960): Development of Primary Hepatic Carcinoma in Rats by Long Term Feeding with $\mathrm{N}$ Yellowed Rice by Penicillium islandicum Sopp-with Study on Influence of Fungus-growing Rice on DAB Carcino- $\odot$ genesis in Rats, Proc. Fapanese Cancer Assoc. (1960), 18th General Meeting, November 1959, p. I 17.

SAKuraI, Y. (I96r): Antitumour Activity of Derivatives of Nitrogen Mustard containing one 2-chlorethyl Group, Cancer Chemotherapy Reports (in press).

Takizawa, N., and Murayama, H. (I960): Experimental Induction of Sarcoma in Mice with Administration of Invert Sugar, prepared from Sucrose by Hydrolysis, Proc. Fapanese Cancer Assoc. (1960), I 8th General Meeting, November 1959, p. 128 .

Tsutsui H. (1918): Artificially-produced Cancroid in the Mouse, Gann, 12, 17.

YAMAGIWA, K., and ICHIKAWA, K. (1916): Experimentelle Studie über die Pathogenese der Epithelialgeschwülste Mitt. med. Fak. Tokio, 15, 295.

Yoshida, T. (1934): Development of Experimental Hepatoma by Use of $o$-amido-azotoluene, with particular reference to Gradual Changes in Liver up to Time of Development of Cancer, Trans. Fap. path. Soc., $24,523$. 